\title{
Fatal bilateral lower-limb deep vein thrombosis and pulmonary embolism following single digit replantation
}

\author{
Anderson SM Leung, Margaret WM Fok *, Boris KK Fung
}

\section{A B S T R A C T}

Venous thromboembolism in hand surgery is rare. There is no report in the literature on postoperative mortality from venous thromboembolism following microsurgery in upper limbs. We report the case of a 56-year-old Chinese man who died from pulmonary embolism as a result of bilateral lowerlimb deep vein thrombosis following prolonged surgery under general anaesthesia after replantation of a finger. This case raises awareness of the need for precautions against venous thromboembolism following prolonged microsurgery and identification of high-risk patients.

\section{Hong Kong Med J 2015;21:283-5}

DOI: $10.12809 / \mathrm{hkmj} 144262$

ASM Leung, MB, BS, MHKICBSC

MWM Fok *, FRCSEd(Orth), FHKAM (Orthopaedic Surgery)

BKK Fung, FRCSEd(Orth), FHKAM (Orthopaedic Surgery)

Department of Orthopaedics and Traumatology, Queen Mary Hospital, Pokfulam, Hong Kong

* Corresponding author: margaret_fok@yahoo.com

\section{Introduction}

Venous thromboembolism (VTE) is a condition that includes both deep vein thrombosis (DVT) and pulmonary embolism (PE). The formation of thrombi is associated with the Virchow's triad, ie circulatory stasis, vascular wall injury, and a hypercoagulable state. Most data of VTE in orthopaedic surgeries are based on studies of patients who undergo hip or knee arthroplasty. The risk of VTE following lowerlimb surgery is noted to be considerably higher than those following upper-limb surgery. To date, there has been no evidence to support the prescription of VTE prophylaxis in upper-limb operations.

\section{Case report}

In June 2013, a 56-year-old, non-obese, Chinese carpenter, who enjoyed good past health and was a non-smoker, sustained injuries to both his left ring finger and little finger while using an electric saw. His left ring finger was amputated at the level of the middle phalanx and his little finger was nearly amputated at the distal interphalangeal joint level. No other site of injury was noted (Fig a). He presented to our hospital 1 hour after the injury. Upon arrival he was haemodynamically stable.

Due to the severe soft tissue contamination of the finger stumps (Fig b), options of either

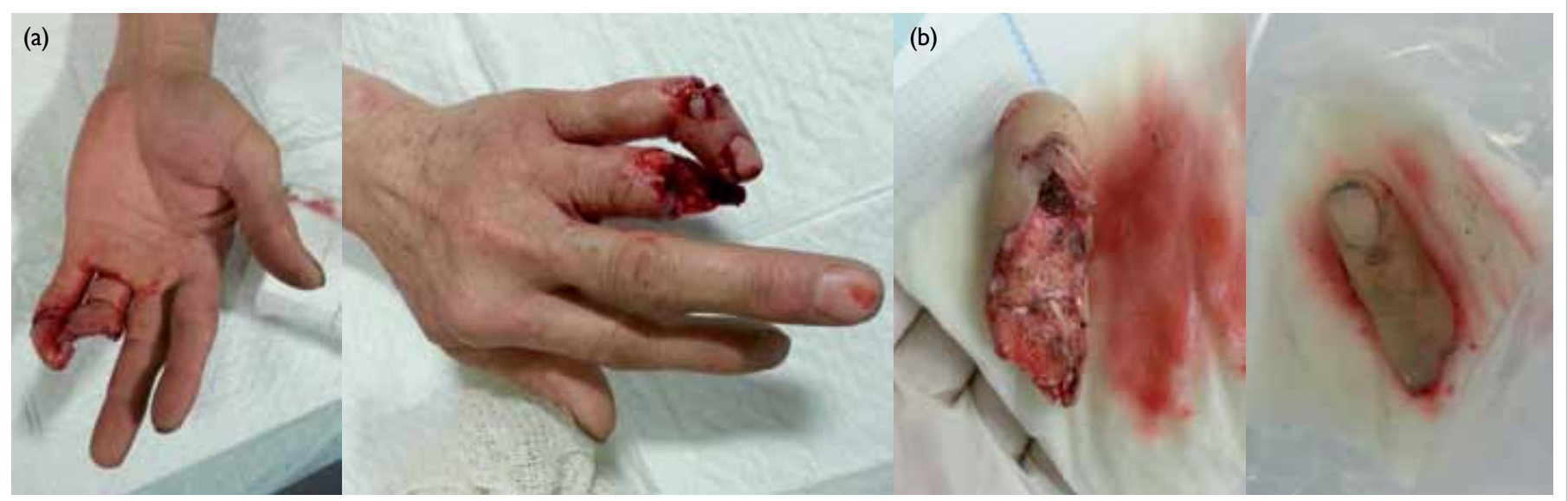

FIG. (a) Amputated left ring finger and near-amputated left little finger. (b) Left ring finger stump with severe soft tissue contamination 


\section{進行斷指再接植手術後出現雙側下肢深靜脈血栓 和肺栓塞導致死亡 \\ 梁紹明、霍奐雯、馮國強}

於手部外科手術後出現靜脈血栓栓塞很罕見, 文獻中並無關於在上肢 進行顯微手術後出現靜脈血栓栓塞導致死亡的病例報告。本文報告一 名56歲華籍男性, 在全身麻醉的情況下進行斷指再接植手術後出現雙 側下肢深靜脈血栓, 最終因肺動脈栓塞死亡。這病例顯示長時間施行 顯微手術後要防範靜脈血栓栓塞的產生, 並要及早識別高危患者。 replantation or revision amputation for the ring finger was discussed with the patient. Subsequent emergency operation was arranged for attempted replantation of his ring finger, and wound debridement and fixation of his left little finger. Revascularisation of the ring finger was attempted thrice, including use of a vein graft. However, due to the inability to achieve sustained blood flow to the amputated stump, revision amputation was performed. Meanwhile, the open wound of the little finger was debrided, and the fracture of the finger was temporarily fixed with axial $\mathrm{K}$ wire. The operation lasted 6 hours 25 minutes, with a total anaesthetic time of 7 hours 12 minutes. The fluid balance was $+2450 \mathrm{~mL}$. He regained full consciousness in the recovery room, with good breathing and oxygen saturation. Antibiotics were continued and he was transferred back to a general ward.

The operation was completed at 4 am the next day and his vital signs remained stable throughout. He offered no complaints in the morning round and was able to mobilise and walk to the washroom where he sustained an unwitnessed fall. He had neither preceding chest pain, headache, nor

BOX. Risk factors for venous thromboembolism ${ }^{3}$

- Active cancer or cancer treatment

- Age over 60 years

- Critical care admission

- Dehydration

- Known thrombophilias

- Obesity (body mass index $>30 \mathrm{~kg} / \mathrm{m}^{2}$ )

- One or more significant medical co-morbidities (eg heart disease; metabolic, endocrine or respiratory pathologies; acute infectious diseases; inflammatory conditions)

- Personal history or first-degree relative with a history of venous thromboembolism

- Use of hormone replacement therapy

- Use of oestrogen-containing contraceptive therapy

- Varicose veins with phlebitis swelling and pain over his lower limbs, and did not lose consciousness. He developed tachycardia, tachypnoea, and desaturation after being helped to his bed. Echocardiogram revealed sinus tachycardia. He started developing chest discomfort with subsequent witnessed arrest 40 minutes later. Cardiac monitoring revealed pulseless electrical activity. Cardiopulmonary resuscitation was started immediately with injection of adrenaline. Bedside echocardiogram revealed no pericardial effusion but there was no response to resuscitation and the patient succumbed 35 minutes later. Postmortem examination revealed bilateral DVT in the calf muscles. Both lungs were markedly congested, with occluding thromboemboli noted in the hilar main pulmonary arteries and their main branches. No other thromboemboli were noted.

\section{Discussion}

Lower limb surgery is a risk factor for VTE events. The prevalence of DVT in patients who undergo hip fracture surgery and hip or knee arthroplasty ranges from $40 \%$ to $60 \% .{ }^{1,2}$ Clinical or fatal PE in Hong Kong Chinese patients is even rarer. ${ }^{2}$

With regard to VTE following upper-limb surgery, nine VTE events have been reported. These comprised seven PEs following total elbow arthroplasty (of which three were fatal), one nonfatal PE after distal radius fixation following acute fracture, and one non-fatal PE following revision osteosynthesis of the proximal diaphysis of ulna. ${ }^{3}$ There has been no reported incidence in the literature of VTE following microsurgery.

It is difficult to determine whether microsurgery is completely risk-free for VTE. Prolonged surgery may involve prolonged immobilisation and blood loss that in turn increases the risk of VTE, based on Virchow's triad. It is thus possible that prophylaxis for VTE is necessary in microsurgery when the operating time is expected to be long, for instance, in finger replantations or freeflap surgeries.

Currently there is no guideline on VTE prophylaxis for microsurgeries. The British Society for Surgery of the $\mathrm{Hand}^{4}$ considers upper-limb procedures under general anaesthesia for more than 90 minutes and/or with one risk factor for VTE $\left(\right.$ Box $\left.^{3}\right)$ as moderate-risk procedures. It recommends use of mechanical compression devices in the operating room and/or until the patient becomes ambulatory. With the risk of bleeding in mind, low-molecularweight heparin (LMWH) may be started no less than 6 hours postoperatively in selected patients and continued until they are fully ambulatory. ${ }^{3}$ None of these recommendations apply specifically to hand or microsurgeries.

In addition to LMWH, the National Institute for Health and Care Excellence clinical guideline 
and the American College of Chest Physicians (ACCP) also mention the newer non-vitamin $\mathrm{K}$ antagonist oral anticoagulants (NOACs). ${ }^{5}$ This group of drugs is associated with a rapid onset of action and predictable pharmacokinetics and pharmacodynamics. There are also fewer interactions with food and other drugs. The ACCP recommends the use of VTE prophylaxis for a minimum of 10 to 14 days following major orthopaedic surgery. In patients who undergo total joint replacement, the ACCP suggests the use of LMWH in preference to other agents (eg fondaparinux, apixaban, dabigatran, rivaroxaban, low-dose unfractionated heparin, adjusted-dose vitamin $\mathrm{K}$ antagonist or aspirin), irrespective of the concomitant use of an intermittent pneumatic compression device. For those patients who refuse injections, apixaban or dabigatran is recommended. However, the available studies (eg RE-MODEL trial, RECORD trial and ADVANCE2 study) and guidelines for VTE prophylaxis focus on total joint replacement surgeries. ${ }^{6}$ There are no recommendations on the use of NOACs in microsurgeries.

When prescribing VTE prophylaxis, it is important to balance the associated benefits and risks. In the case of mechanical compression, in view of its low-risk profile, it should be offered to all patients who undergo prolonged microvascular procedures, for example replantation, until they are fully ambulatory. The application of mechanical compression on both lower limbs may nonetheless be limited if donor sites for blood vessels and other tissues are anticipated from a lower limb.
Based on available evidence, we suggest that all patients who undergo microsurgery should have mechanical compression prophylaxis. Additional pharmacological prophylaxis should be considered for those who are at relatively high risk of developing VTE, for example, patients who have more than one risk factor, those in whom upper limb or tumour surgery will exceed 90-minute duration, and/or those in whom there will be prolonged postoperative immobilisation.

\section{References}

1. Geerts WH, Bergqvist D, Pineo GF, et al. Prevention of venous thromboembolism: American College of Chest Physicians Evidence-Based Clinical Practice Guidelines (8th Edition). Chest 2008;133(6 Suppl):381S-453S.

2. Mok CK, Hoaglund FT, Rogoff SM, Chow SP, Ma A, Yau AC. The incidence of deep vein thrombosis in Hong Kong Chinese after hip surgery for fracture of the proximal femur. Br J Surg 1979;66:640-2.

3. Roberts DC, Warwick DJ. Venous thromboembolism following elbow, wrist and hand surgery: a review of the literature and prophylaxis guidelines. J Hand Surg Eur Vol 2014;39:306-12.

4. The British Society for Surgery of the Hand. VTE Guidelines. Available from: http://www.bssh.ac.uk/ education/guidelines/vteguidelines. Accessed 2 Jul 2012.

5. Beyer-Westendorf J, Ageno W. Benefit-risk profile of non-vitamin $\mathrm{K}$ antagonist oral anticoagulants in the management of venous thromboembolism. Thromb Haemost 2015;113:231-46.

6. Saraf K, Morris P, Garg P, Sheridan P, Storey R. Nonvitamin $\mathrm{K}$ antagonist oral anticoagulants (NOACs): clinical evidence and therapeutic considerations. Postgrad Med J 2014;90:520-8. 